J Clin Obstet Gynecol. 2021;31(1):14-9

\title{
Evaluation of Prognostic Nutritional Status in Late-onset Fetal Growth Restriction
}

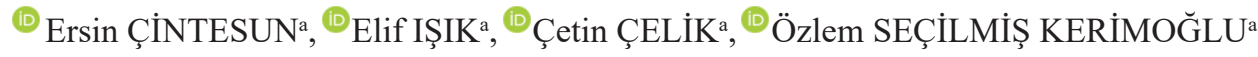 \\ aDepartment of Obstetrics and Gynecology, Selçuk University Faculty of Medicine, Konya, TURKEY
}

\begin{abstract}
Objective: We aimed to investigate the relationship between Onodera's prognostic nutrition index (OPNI) and controlling nutritional status index (CONUT) that are used for evaluating the nutritional status and late-onset fetal growth restriction (FGR). Material and Methods: This study was a prospective cross-sectional study on 141 patients, which was conducted at the Medical Faculty of Selcuk University. The study included 62 women with late-onset FGR and 79 control patients. The control group was randomly selected from among pregnant women in the $32^{\text {nd }}-37^{\text {th }}$ gestational weeks with pre-pregnancy body mass index (BMI) $<25 \mathrm{~kg} / \mathrm{m}^{2}$, without any systemic and metabolic disease, without substance use such as alcohol, cigarettes, and without the use of any drugs. The OPNI and CONUT values for each patient were measured within 3 days prior to the delivery. Results: Age, gravida, parity, and birth week were similar between the groups ( $>0.05$ ). Before birth and pre-pregnancy weight, height, and pre-pregnancy BMI were significantly different between the groups $(\mathrm{p}<0.05)$. Considering the mode of delivery among the groups, the vaginal birth rate was higher in the control group $(67.1 \%$ vs. $32.9 \%)$, and the cesarean section rate was higher in patients with late-onset FGR (58.1\% vs. $41.9 \%$ ). Neutrophil-lymphocyte ratio and OPNI values were similar between the groups ( $\mathrm{p}>0.05)$. We classified the CONUT score calculation according to two different cut-off values, and both classifications were similar between the groups ( $p>0.05$ ). Conclusion: It has been shown that the OPNI and CONUT scores, which are used to predict nutritional status and prognosis in cancer and chronic diseases, are not useful to predict the late-onset FGR.
\end{abstract}

Keywords: Albumin; fetal growth restriction; nutrition; placenta

Fetal growth restriction (FGR) is one of the most common causes of adverse perinatal outcomes, affecting about $3-9 \%$ of all pregnancies. ${ }^{1}$ About 30\% of preventable stillbirths are due to FGR. ${ }^{2}$ Diagnosing FGR is very important due to its coexistence of perinatal death, poor neurodevelopment, preterm delivery, and other long-term results. ${ }^{3,4}$ In the etiology of FGR, nulliparity, advanced maternal age, low body mass index (BMI) $\left(<18.5 \mathrm{~kg} / \mathrm{m}^{2}\right)$, ethnicity, maternal consumption of alcohol or drug use of cocaine, heroin, and cigarette smoke, and teratogenic medication that affect fetal growth are defined..$^{5-8}$ In addition, it has been shown that maternal malnutrition is responsible for $40 \%$ of the etiology of FGR on a global scale. ${ }^{9}$

FGR is defined as an estimated fetal weight (EFW) $<10^{\text {th }}$ percentile due to a pathologic process, meaning that the smaller fetus is failing to reach its natural growth potential. ${ }^{10}$ Although the $10^{\text {th }}$ percentile limit is currently used for the diagnosis of FGR, other parame- ters have also been proposed in the distinction of FGR and small for gestational age (SGA) ${ }^{11,12}$ In some expert reports, it is desired to have one of these three criteria to distinguish between FGR and SGA: EFW $<3^{\text {rd }}$ percentile, uterine artery Doppler pulsatility index $>95^{\text {th }}$ percentile, and cerebro placental ratio $<5^{\text {th }}$ percentile. ${ }^{11,12}$ FGR is divided into two phenotypes as characterized by differences in etiology, onset, fetoplacental Doppler values, relation with preeclampsia (PE), and potential for morbidity and mortality: early FGR (gestational age $<32$ weeks) and late FGR (gestational age $\geq 32$ weeks). ${ }^{13}$ Early-onset FGR is strongly associated with poor placental invasion from early pregnancy, which is thought to explain the common association with $\mathrm{PE}$, whereas late-onset FGR is onset in late pregnancy and its placental findings are generally less specific. ${ }^{14}$ Ultrasonographic markers are mostly used in the diagnosis and prognosis of FGR. Ultrasonographic measurements vary by device and healthcare professional,

Correspondence: Ersin ÇINTESUN

Department of Obstetrics and Gynecology, Selçuk University Faculty of Medicine, Konya, TURKEY

E-mail: ersincintesun@gmail.com

Peer review under responsibility of Journal of Clinical Obstetrics \& Gynecology. 
thus this method is not reliable enough. There is no certain biochemical marker used for the diagnosis, prognosis, and subclassification of FGR.

There are many studies in the literature about nutritional status. Although the majority of these studies are on patients with cancer, some studies explored the relationship between various systemic diseases and nutritional status. ${ }^{15-17}$ Onodera's prognostic nutritional index (OPNI) and the controlling nutritional status index (CONUT) scoring systems are frequently used indexes. In these scores, a calculation is made using serum albumin, lymphocyte, and total cholesterol values. In this study, it was aimed to investigate the relationship between late-onset FGR, which is characterized by abnormal placental perfusion, and maternal nutrition. What inspires this study is the knowledge that maternal nutritional status is effective in FGR etiology.

\section{MATERIAL AND METHODS}

\section{PATIENTS AND STUDY DESIGN}

This study was a prospective cross-sectional study on 141 patients, which was conducted at the Medical Faculty of Selcuk University between October 2019 and March 2020. Written informed consent was obtained from all patients. The study was approved by the Selcuk University local ethics committee (Reg.No: 2019/293) on 30 October 2019. The study was performed in accordance with the principles of the World Medical Association Declaration of Helsinki Ethical Principles for Medical Research.

Sixty-two women with late-onset FGR and 79 control patients were included. The control group was randomly selected among patients who conformed to the inclusion criteria. The inclusion criteria were being aged 18-35 years, being at 32-37 gestational weeks, having pre-pregnancy BMI $<25 \mathrm{~kg} / \mathrm{m}^{2}$, having no systemic and metabolic disease, not using substances such as alcohol, cigarettes and any drugs, and having no gastrointestinal disease-causing malnutrition.

Patients at 32-37 weeks' gestation who had no systemic disease such as PE and gestational diabetes, with an EFW below the $10^{\text {th }}$ percentile were included as the late-onset FGR group. The patients were diagnosed after 32 weeks of gestation according to firsttrimester ultrasonographic measurements performed when the last menstrual period was unknown or those whose measurements are incompatible. Serum samples of the late-onset group were taken in the morning before breakfast.

\section{EVALUATION OF NUTRITIONAL SCREENING TOOLS}

The OPNI and CONUT values for each patient were measured in the peripheral blood within 3 days prior to the delivery.

The OPNI uses serum albumin and total lymphocyte count, and is calculated using the following formula: OPNI $=10 \times$ serum albumin $(\mathrm{g} / \mathrm{dL})+0.005 \times$ total lymphocyte count $\left(\mathrm{mm}^{3}\right)$.

CONUT, with a score between 0 and 12, uses serum albumin, total cholesterol, and total lymphocyte count as indicators of protein reserves, caloric depletion, and impaired immune defense, respectively. The CONUT score calculation is achieved in two different ways. In the first calculation, there are four assessments as normal, light, moderate, and severe. ${ }^{18}$ In the second calculation, the CONUT is scored as two categories, low and high. ${ }^{19}$ In our study, we defined the first classification as CONUT 1 score and the second classification as CONUT 2 score.

\section{STATISTICAL ANALYSIS}

Statistical analysis was performed using the Statistical Package for the Social Sciences (SPSS) version 21.0 software (IBM Corp., Armonk, NY, USA). The distribution of variables was tested for normality using histograms and the Shapiro-Wilk W-test. Parametric continuous data are presented as means \pm standard deviation, nonparametric continuous data are presented as medians (min-max), and categorical variables are expressed as numbers (percentages). Comparisons between the two groups with normally distributed variables were performed using an independent samples t-test. The differences between the groups without normal distribution were compared with the Mann-Whitney U test, while groups with categorical variables were compared with the Pearson chi-squared test. $p<0.05$ was considered statistically significant. 


\section{RESULTS}

The patients' characteristics are summarized in Table 1. Seventy-nine patients in the normal group and 62 patients in the late-onset FGR group were compared. Age, gravida, and parity were similar between the groups $(p>0.05)$. Birth week was similar between the groups $(p>0.05)$. Before birth and pre-pregnancy weight, height, and prepregnancy BMI were significantly different between the groups $(p<0.05)$. Before birth BMI was similar between the groups $(p>0.05)$. Among the groups, considering the mode of delivery, the vaginal delivery rate was higher in the control group $(67.1 \%$ vs. $32.9 \%)$, and cesarean section was observed more frequently in the late-onset FGR group (58.1\% vs. $41.9 \%)$.

The results of the comparison of hematologic, biochemical, OPNI and CONUT results between the groups are summarized in Table 2. Albumin, total cholesterol, lymphocyte, neutrophil, low-density lipoprotein cholesterol, high-density lipoprotein cholesterol, and triglyceride values were similar between the groups $(p>0.05)$. Neutrophil-lymphocyte ratio (NLR) and OPNI values were also similar between the groups $(p>0.05)$. We classified the CONUT score calculation according to two different cut-off values and both classifications were similar between the groups $(p>0.05)$.

\section{DISCUSSION}

There is no study in pregnant patients in the literature about OPNI and CONUT scores. These two scores are mostly used for the purpose of prognosis and long-term survival in cancer, dialysis, and critical patients. ${ }^{15,18,20}$ In our study, although before birth and pre-pregnancy weight, height, and pre-pregnancy BMI were significantly different between the groups, no significant difference was found between the NLR, OPNI, and CONUT scoring system measurements and the groups.

OPNI and CONUT scores are nutritional indicators that function as a prognostic factor for many malignancies and other diseases. The OPNI score was defined in 1984 by Ondera et al. in a study of patients with terminal cancer. ${ }^{21}$ These scores are calculated using albumin, total cholesterol, and lymphocyte counts, and calculated by assuming that it represents albumin protein reserve and total cholesterol calorie depletion, and the total lymphocyte count represents an impaired immune defense. Studies on malignancy have often been found to reflect the clinical situation proper. In a study about patients with epithelial ovarian cancers by $\mathrm{Li}$ et al., the authors found that the CONUT score was an independent prognostic factor for overall survival. ${ }^{20}$ In another study on patients with colorectal cancer, researchers found that the CONUT score was very effective in predicting prog-

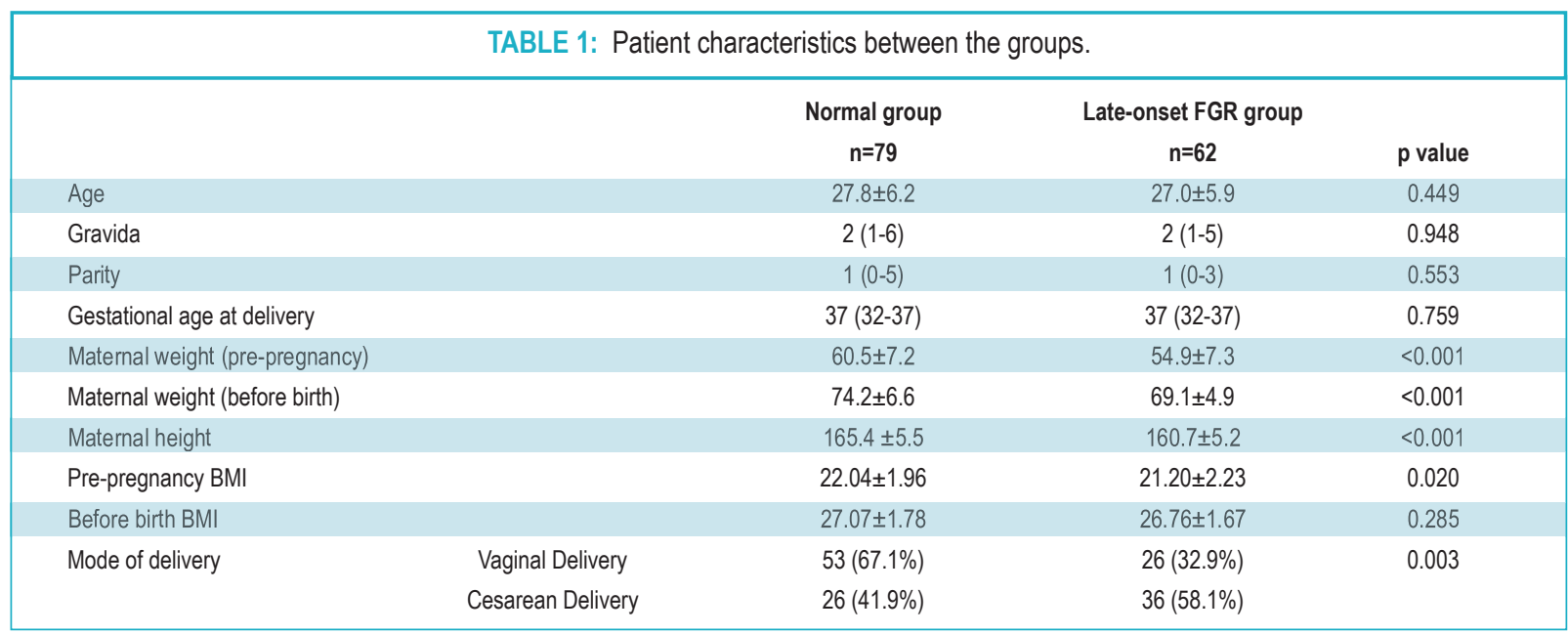

Values are expressed as means $\pm S D, n(\%)$, or median (min-max); FGR: Fetal growth restriction; BMI: Body mass index. 


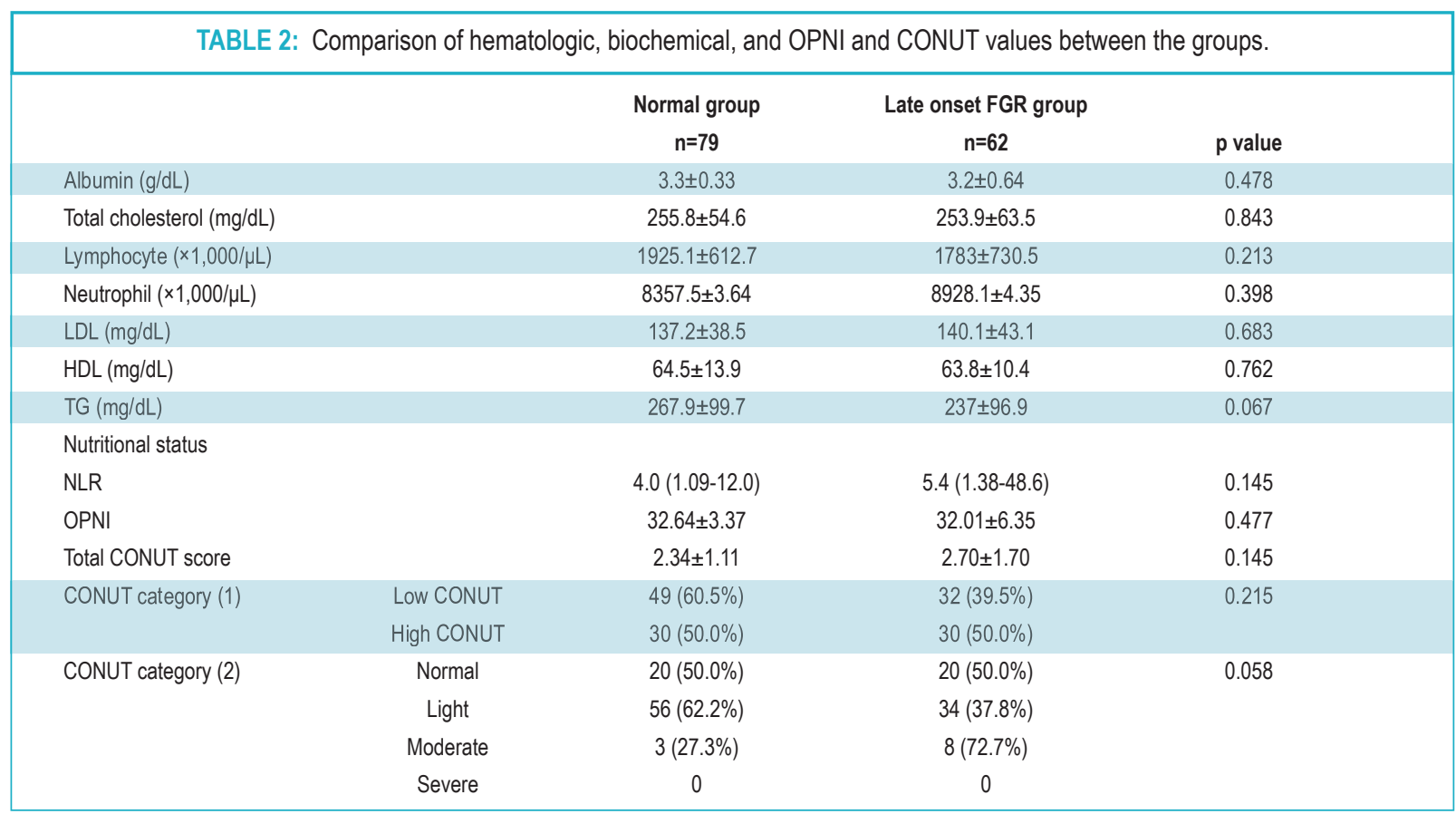

Values are expressed as means \pm SD, $n$ (\%), or median (min-max); OPNI: Onodera's prognostic nutrition index; CONUT: Controlling nutritional status index; FGR: Fetal growth restriction; LDL: Low-density lipoprotein cholesterol; HDL: High-density lipoprotein cholesterol; TG: Triglyceride; NLR: Neutrophil to lymphocyte ratio.

nosis in these patients. ${ }^{19}$ Similar to the CONUT score, the OPNI score was found effective in determining prognosis in malignant diseases. ${ }^{22,23}$ In addition to malignancy, nutritional risk assessment has been used in studies on chronic diseases such as schizophrenia, and it has been stated that it might be meaningful. ${ }^{16} \mathrm{In}$ our study, the effect of CONUT and OPNI scores on late-onset FGR could not be demonstrated. There may be several reasons for this result. Today's pregnant women typically do not have serious malnutrition statuses such as in cancer or chronic disease, and we do not question patients' daily diets and calorie intake.

Maternal malnutrition remains unacceptably a major problem in poor countries. ${ }^{24}$ Maternal malnutrition is related to an increased risk of maternal morbidity and mortality, with a range of adverse pregnancy outcomes such as low birth weight and preterm delivery, which is highly associated with a risk of neonatal morbidity and mortality. ${ }^{7,24}$ Generally, maternal malnutrition can reduce nutrient delivery to the fetus by disrupting placental formation, leading to a reduction in placenta size, changes in his- tomorphology, and reduced blood flow. ${ }^{25}$ In the animal study of Roberts et al., it was shown that maternal food restriction not only decreased fetal and placental weights but also caused severe functional impairment in the placenta. ${ }^{26}$ It has been observed in the history that women exposed to severe malnutrition, known as the Dutch Famine of 1944-45, gave birth to babies with small placenta and low birth weight. ${ }^{27}$ In embryonic and fetal development, it provides important contributions to macronutrients (vitamin A, calcium, zinc, iron, etc.) as well as micronutrients. Micronutrient deficiencies also cause significant morbidity and mortality. ${ }^{28}$ It has been shown that low weight gain and FGR are common in pregnant women due to malnutrition, especially in developing countries. ${ }^{9,29}$ In a prospective study by Ferdous et al., it was shown that in pregnant women with low BMI, fetal birth weight was below the general population growth average..$^{29}$ In our study, these two scoring systems were similar between the groups. No significant difference was found because this study was conducted in a country with a low number of severe malnutrition cases. These criteria demon- 
strate long-term malnutrition, which could be another explanation for our results. In addition, serum micronutrient values are not used in the scoring systems we use in comparison.

Numerous physiologic changes happen in a mother during pregnancy in response to her increased metabolic needs and providing fetal nutrition. Various hormonal and cell-mediated immunologic changes occur to maintain pregnancy. ${ }^{30}$ Although normal total leukocyte counts are higher in pregnant women than in non-pregnant women, the main change in lymphocytes is in subtype change. ${ }^{31}$ Serum albumin concentrations decrease during pregnancy. In late pregnancy, albumin levels are close to 3.0 $\mathrm{g} / \mathrm{dL}$, whereas in non-pregnant women, it is around $4.3 \mathrm{~g} / \mathrm{dL}$. However, the total body albumin increase is low compared to plasma volume increase during pregnancy. ${ }^{32}$ Due to insulin resistance and increased estrogen levels at pregnancy, concentrations of lipids, lipoproteins, and apolipoproteins in plasma also increase significantly during pregnancy. ${ }^{33}$ Triacylglycerol and cholesterol levels in total serum cholesterol, very-low-density lipoproteins, LDLs, and HDLs are increased during the third trimester compared with non-pregnant women. ${ }^{34}$ After delivery, the concentrations of these lipids, lipoproteins, and apolipoproteins decreases. In patients with cancer, serum albumin, lymphocytes, and total cholesterol levels tend to decrease. ${ }^{35}$ In our study, although pre-pregnancy weight and BMI values were low in the FGR patient group, these two scoring systems did not differ significantly. This may be due to the fact that albumin, cholesterol, and lymphocytes behave differently between pregnancy and cancer, and the compensatory mechanisms of pregnancy make these parameters unusable.

The limitation of our study is the low sample size that the actual beginning time of FGR is unknown, and the cut-off values of OPNI and CONUT scores in pregnant women are also unknown. In addition, it is an obstacle that these scoring systems are not adapted to the physiologic changes that occur in pregnant women. The strength of this study is that these malnutrition scores have not been studied before in pregnant women, especially those with FGR.

\section{CONCLUSION}

As a result, it has been shown that the OPNI and CONUT scores, which are used to predict nutritional status and prognosis in cancer and chronic diseases, are not useful in late-onset FGR. The diagnosis of FGR is made using ultrasonography, but evaluations are dependent on the performing physician. More accurate methods such as biochemical parameters should be searched in FGR. The developments of new scoring systems in malnutrition that are adapted to changes that occur in pregnancy are needed.

\section{Source of Finance}

During this study, no financial or spiritual support was received neither from any pharmaceutical company that has a direct connection with the research subject, nor from a company that provides or produces medical instruments and materials which may negatively affect the evaluation process of this study.

\section{Conflict of Interest}

No conflicts of interest between the authors and / or family members of the scientific and medical committee members or members of the potential conflicts of interest, counseling, expertise, working conditions, share holding and similar situations in any firm.

\section{Authorship Contributions}

Idea/Concept: Ersin Çintesun, Elif Işık, Çetin Çelik, Özlem Seçilmiş Kerimoğlu; Design: Ersin Çintesun, Özlem Seçilmiş Kerimoğlu; Control/Supervision: Özlem Seçilmiş Kerimoğlu, Çetin Çelik; Data Collection and/or Processing: Ersin Çintesun, Elif Ișık; Analysis and/or Interpretation: Ersin Çintesun, Çetin Çelik; Literature Review: Ersin Çintesun, Elif Işık, Çetin Çelik, Özlem Seçilmiş Kerimoğlu; Writing the Article: Ersin Çintesun; Critical Review: Ersin Çintesun, Özlem Seçilmiş Kerimoğlu, Çetin Çelik; References and Fundings: Ersin Çintesun, Elif Işık, Çetin Çelik, Özlem Seçilmiş Kerimoğlu; Materials: Özlem Seçilmiş Kerimoğlu. 


\section{REFERENCES}

1. Nardozza LM, Caetano AC, Zamarian AC, Mazzola JB, Silva CP, Marçal VM, et al. Fetal growth restriction: current knowledge. Arch Gynecol Obstet. 2017;295(5):1061-77. [Crossref] [PubMed]

2. International Stillbirth Alliance Collaborative for Improving Classification of Perinatal Deaths, Flenady V, WojcieszekAM, Ellwood D, Leisher SH, Erwich JJHM, Draper ES, et al. Classification of causes and associated conditions for stillbirths and neonatal deaths. Semin Fetal Neonatal Med. 2017;22(3):176-85. [Crossref] [PubMed]

3. Miller SL, Huppi PS, Mallard C. The consequences of fetal growth restriction on brain structure and neurodevelopmental outcome. J Physiol. 2016;594(4):807-23. [Crossref] [PubMed] [PMC]

4. Francis JH, Permezel M, Davey MA. Perinatal mortality by birthweight centile. Aust $\mathrm{N} Z \mathrm{~J} \mathrm{Ob}-$ stet Gynaecol. 2014;54(4):354-9. [Crossref] [PubMed]

5. Shah PS; Knowledge Synthesis Group on Determinants of LBW/PT births. Parity and low birth weight and preterm birth: a systematic review and meta-analyses. Acta Obstet Gynecol Scand. 2010;89(7):862-75. [Crossref] [PubMed]

6. Odibo AO, Nelson D, Stamilio DM, Sehdev HM, Macones GA. Advanced maternal age is an independent risk factor for intrauterine growth restriction. Am J Perinatol. 2006;23(5):325-8. [Crossref] [PubMed]

7. Han Z, Mulla S, Beyene J, Liao G, McDonald SD; Knowledge Synthesis Group. Maternal underweight and the risk of preterm birth and low birth weight: a systematic review and meta-analyses. Int $\mathrm{J}$ Epidemiol. 2011;40(1):65-101. [Crossref] [PubMed]

8. Jaddoe VW, Bakker R, Hofman A, Mackenbach JP, Moll HA, Steegers EA, et al. Moderate alcohol consumption during pregnancy and the risk of low birth weight and preterm birth. The generation R study. Ann Epidemiol. 2007;17(10):834-40. [Crossref] [PubMed]

9. Villar J, Papageorghiou AT, Pang R, Ohuma EO, Cheikh Ismail L, Barros FC, et al; International Fetal and Newborn Growth Consortium for the 21st Century (INTERGROWTH-21st). The likeness of fetal growth and newborn size across non-isolated populations in the INTERGROWTH-21st Project: the Fetal Growth Longitudinal Study and Newborn Cross-Sectional Study. Lancet Diabetes Endocrinol. 2014;2(10):781-92. [Crossref] [PubMed]

10. ACOG Practice bulletin no. 134: fetal growth restriction. Obstet Gynecol. 2013;121(5):112233. [Crossref] [PubMed]

11. Baschat AA. Neurodevelopment following fetal growth restriction and its relationship with antepartum parameters of placental dysfunction. Ultrasound Obstet Gynecol. 2011;37(5):50114. [Crossref] [PubMed]
12. Figueras F, Gratacos E. An integrated approach to fetal growth restriction. Best Pract Res Clin Obstet Gynaecol. 2017;38:48-58. [Crossref] [PubMed]

13. Savchev S, Figueras F, Sanz-Cortes M, CruzLemini M, Triunfo S, Botet F, et al. Evaluation of an optimal gestational age cut-off for the definition of early-and late-onset fetal growth restriction. Fetal Diagn Ther. 2014;36(2):99105. [Crossref] [PubMed]

14. Crispi F, Llurba E, Domínguez $C$, Martín-Gallán $P$, Cabero L, Gratacós E. Predictive value of angiogenic factors and uterine artery Doppler for early- versus late-onset pre-eclampsia and intrauterine growth restriction. Ultrasound Obstet Gynecol. 2008;31(3):303-9. [Crossref] [PubMed]

15. Hu Y, Shen J, Liu R, Feng Z, Zhang C, Ling L, et al. Prognostic value of pretreatment prognostic nutritional index in non-small cell lung cancer: A systematic review and meta-analysis. Int J Biol Markers. 2018;33(4):372-8. [Crossref] [PubMed]

16. Tsai MT, Chang TH, Wu BJ. Prognostic impact of nutritional risk assessment in patients with chronic schizophrenia. Schizophr Res. 2018;192:137-41. [Crossref] [PubMed]

17. Kang SH, Cho KH, Park JW, Yoon KW, Do JY Onodera's prognostic nutritional index as a risk factor for mortality in peritoneal dialysis patients. J Korean Med Sci. 2012;27(11): 1354-8. [Crossref] [PubMed] [PMC]

18. Kuroda $D$, Sawayama $H$, Kurashige J, Iwatsuki M, Eto T, Tokunaga R, et al. Controlling Nutritional Status (CONUT) score is a prognostic marker for gastric cancer patients after curative resection. Gastric Cancer. 2018;21(2):204-12. [Crossref] [PubMed]

19. Yamamoto $M$, Saito $H$, Uejima $C$, Tanio $A$, Tada $Y$, Matsunaga T, et al. Prognostic Value of Combined Tumor Marker and Controlling Nutritional Status (CONUT) Score in Colorectal Cancer Patients. Yonago Acta Med. 2019;62(1):124-30. [Crossref] [PubMed] [PMC]

20. Li Y, Zhang C, Ji R, Lu H, Zhang W, Li LL, et al. Prognostic significance of the controlling nutritional status (CONUT) score in epithelial ovarian cancer. Int $\mathrm{J}$ Gynecol Cancer. 2020;30(1):74-82. [Crossref] [PubMed]

21. Onodera T, Goseki N, Kosaki G. [Prognostic nutritional index in gastrointestinal surgery of malnourished cancer patients]. Nihon Geka Gakkai Zasshi. 1984;85(9):1001-5. [PubMed]

22. Go SI, Jeon H, Park SW, Kang MH, Kim HG Lee GW. Low pre-treatment nutritional index is significantly related to poor outcomes in small cell lung cancer. Thorac Cancer. 2018;9(11):1483-91. [Crossref] [PubMed] [PMC]

23. Ikeya T, Shibutani M, Maeda K, Sugano K, Nagahara $\mathrm{H}$, Ohtani $\mathrm{H}$, et al. Maintenance of the nutritional prognostic index predicts survival in patients with unresectable metastatic colorectal cancer. J Cancer Res Clin Oncol. 2015;141(2):307-13. [Crossref] [PubMed]

24. Desyibelew HD, Dadi AF. Burden and determinants of malnutrition among pregnant women in Africa: A systematic review and meta-analysis. PLoS One. 2019;14(9): e0221712. [Crossref] [PubMed] [PMC]

25. Belkacemi L, Nelson DM, Desai M, Ross MG Maternal undernutrition influences placentalfetal development. Biol Reprod. 2010;83(3): 325-31. [Crossref] [PubMed]

26. Roberts $C T$, Sohlstrom A, Kind KL, Earl RA, Khong TY, Robinson JS, et al. Maternal food restriction reduces the exchange surface area and increases the barrier thickness of the placenta in the guinea-pig. Placenta. 2001;22(23):177-85. [Crossref] [PubMed]

27. Lumey LH. Compensatory placental growth after restricted maternal nutrition in early pregnancy. Placenta. 1998;19(1):105-11. [Crossref] [PubMed]

28. Hsu CN, Tain YL. The Good, the Bad, and the Ugly of Pregnancy Nutrients and Developmental Programming of Adult Disease. Nutrients. 2019;11(4):894. [Crossref] [PubMed] [PMC]

29. Ferdous $F$, Rashid MH, Ma E, Raqib $R$, Hamada $\mathrm{H}$, Wagatsuma Y. Fetal growth restriction in rural Bangladesh: a prospective study. Trop Med Health. 2018;46:3. [Crossref] [PubMed] [PMC]

30. Sargent IL, Redman CW. Maternal cell-mediated immunity to the fetus in human pregnancy. J Reprod Immunol. 1985;7(2):95-104. [Crossref] [PubMed]

31. Kühnert $M$, Strohmeier $R$, Stegmüller $M$, Halberstadt $E$. Changes in lymphocyte subsets during normal pregnancy. Eur J Obstet Gynecol Reprod Biol. 1998;76(2):147-51. [Crossref] [PubMed]

32. Mendenhall HW. Serum protein concentrations in pregnancy. I. Concentrations in maternal serum. Am J Obstet Gynecol. 1970;106(3):388-99. [Crossref] [PubMed]

33. Herrera E, Ortega-Senovilla H. Lipid metabolism during pregnancy and its implications for fetal growth. Curr Pharm Biotechnol. 2014;15(1):24-31. [Crossref] [PubMed]

34. Lippi G, Albiero A, Montagnana M, Salvagno GL, Scevarolli S, Franchi M, et al. Lipid and lipoprotein profile in physiological pregnancy. Clin Lab. 2007;53(3-4):173-7. [PubMed]

35. Iseki $Y$, Shibutani M, Maeda K, Nagahara H, Ohtani $\mathrm{H}$, Sugano $\mathrm{K}$, et al. Impact of the Preoperative Controlling Nutritional Status (CONUT) score on the survival after curative surgery for colorectal cancer. PLoS One. 2015;10(7): e0132488. [Crossref] [PubMed] [PMC] 